\title{
JUVENTUDE, TRABALHO E DESENVOLVIMENTO: elementos para uma agenda de investigação
}

\author{
Adalberto Cardoso*
}

\begin{abstract}
A crise econômica pós-2008, acompanhada de grandes protestos sociais em toda parte, acendeu a luz vermelha nos países mais ricos quanto às oportunidades de trabalho e estudo dos jovens. Aumentou muito a proporção daqueles que não estudam nem trabalham, em especial na Espanha e na Grécia, mas o fenômeno é disseminado nos países mais ricos. $\mathrm{O}$ artigo mostra que, no Brasil, a condição "nem nem” é estrutural, e propõe um modelo analítico de explicação das transformações ocorridas entre 2000 e 2010. Sugere que as mudanças estruturais por que passou o país e as políticas públicas de redução de barreiras ao acesso à escola e ao mercado de trabalho reduziram o impacto das desigualdades regionais e aumentaram o peso da pobreza na explicação da condição "nem nem" dos jovens.

Palavras chave: Juventude. Mercado de trabalho. Mudanças estruturais. Condição "nem nem”.
\end{abstract} Modelos causais.

\section{APRESENTAÇÃO}

A crise econômica iniciada em 2008, que completa seu quinto ano enquanto escrevo, acendeu a luz vermelha nos países mais ricos do mundo no que respeita às chances de inserção dos jovens no mercado de trabalho. Uma situação que era pensada como típica dos países do sul da Europa (em especial Espanha, Itália e Portugal) disseminou-se pelo continente. Refiro-me à condição "ni ni”, denominação espanhola para os jovens que não estão nem na escola nem trabalhando. Dados para os 34 países da Organização para a Cooperação e o Desenvolvimento Econômico OCDE - revelam que $16 \%$ dos jovens de 15 a 29 anos estavam nessa condição em $2010,{ }^{1}$ sendo que

* Doutor em Sociologia. Professor e pesquisador do Instituto de Estudos Sociais e Políticos da Universidade Estadual do Rio de Janeiro - IESP-UERJ -, Pesquisador Associado do Centro Brasileiro de Análises e Planejamento e do Warwick Institute for Employment Research, Cientista do Nosso Estado da FAPERJ e Pesquisador 1 do CNPq. Rua da Matriz, 82. Cep: 22260-100. Botafogo - Rio de Janeiro, RJ - Brasil. acardoso@iesp.uerj.br

${ }^{1}$ A OCDE utiliza o acrônimo NEET (Neither Employed, nor in Education and Training) para designar o fenômeno dos jovens que não estudam nem trabalham. Ver OCDE (2012). a taxa era de $18 \%$ entre as mulheres e $14 \%$ entre os homens (OCDE, 2012, p. 382).

Em razão da disposição militante dos jovens, depois da crise de 2008, esse quadro de 2010 foi tratado por muitos como crítico, isto é, fruto de surpreendente dissolução das estruturas anteriores de probabilidade de acesso a posições na escola ou no mercado de trabalho. Contudo, olhando os dados da OCDE em mais detalhe, descobre-se que a incidência do fenômeno é bem mais disseminada e extensa no tempo, isto é, a "condição nem nem" não é uma novidade nas dinâmicas social e econômica contemporâneas. Tomando-se o período de 1997 a 2010 , entre os jovens de 20 a 24 anos a média de "nem nem" naqueles países mais ricos nunca foi inferior a 13\%, atingindo o pico de 17,6\% em 2010. ${ }^{2}$ A novidade, então, parece ser o aumento importante da intensidade do fenômeno, concentrado num período muito curto de tempo, que lhe deu estatura de problema social e político de monta.

Neste artigo, não se pretende analisar o fe-

\footnotetext{
${ }^{2}$ Ver a tabela total em http://dx.doi.org/10.1787/888932667520.
} 
nômeno nos países mais ricos, e sim, tomá-los como referência para a análise do caso brasileiro. Por que, entre nós, o problema, também geral e extenso no tempo, não tinha ganhado, até pelo menos meados de 2013, as mesmas tintas explosivas? Depois de comparar as duas realidades e elaborar teoricamente a persistência do problema geracional no mundo contemporâneo, procuro responder a essa pergunta construindo um modelo logístico de explicação da probabilidade de um jovem estar na condição "nem nem" no país, comparando 2000 e 2010 a partir dos dados dos cen-

Gráfico 1 - Proporção de jovens de 15 a 29 anos que não estudam nem trabalham, segundo sexo e faixas de idade, 21 países da União Europeia, 1997-2010

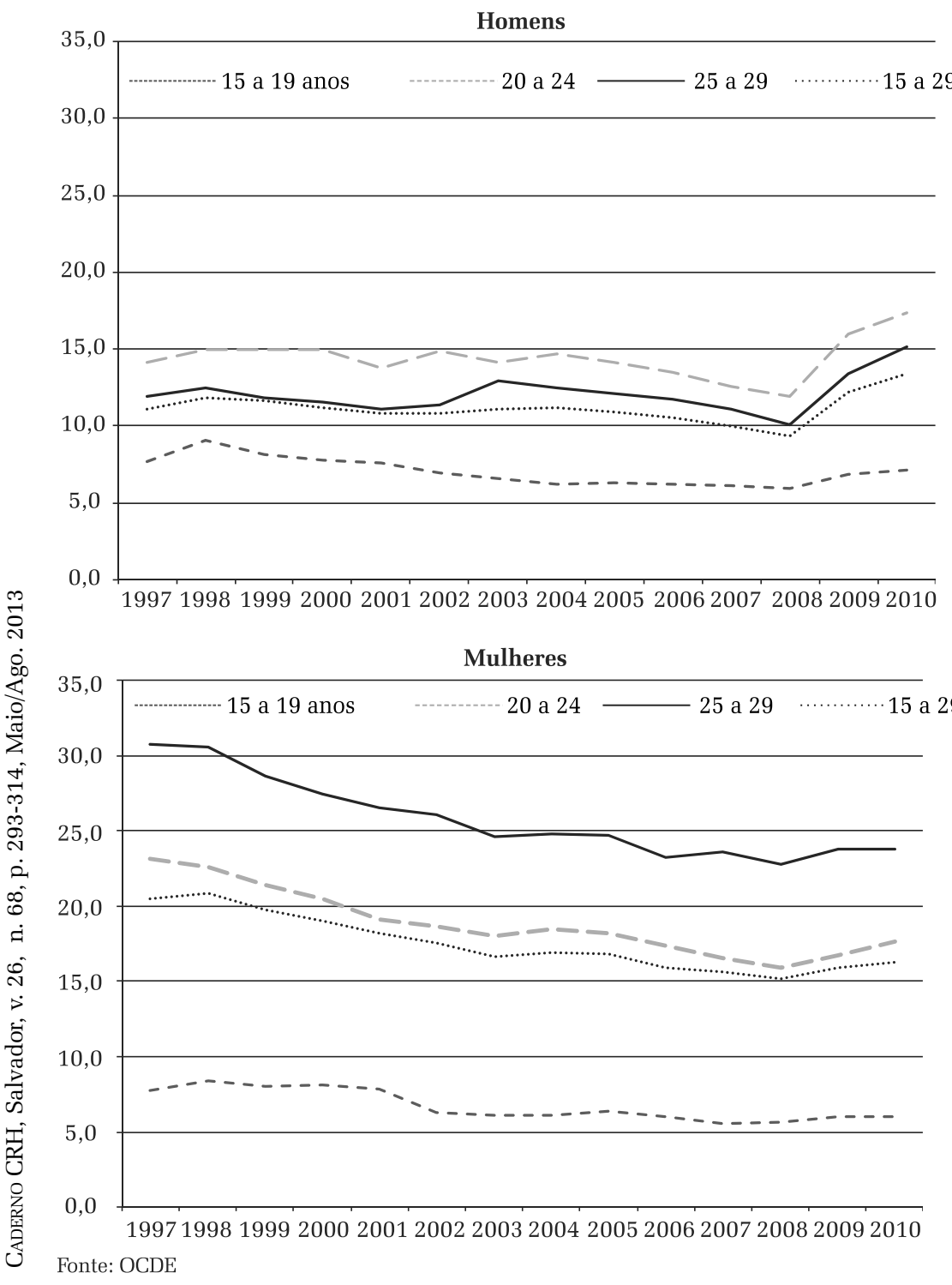

sos demográficos do IBGE. Argumento que a "condição nem nem" é fruto da conjunção de dois feixes de determinantes: de um lado, os contextos de inserção social dos jovens (a família, o sistema escolar e o mercado de trabalho); e, de outro, as trajetórias dos indivíduos. Os dois feixes são marcados por desigualdades de todo tipo, e o objetivo da análise é identificar tendências e mudanças no tempo, formular hipóteses sobre a direção dessas mudanças e seu efeito na relação dos jovens com a condição "nem nem", e, por fim, levantar questões de pesquisa e de políticas públicas para o país, relacionadas ao problema da juventude e sua relação com o trabalho e o desenvolvimento. Um dos principais argumentos sustentados aqui é o de que o caráter estrutural do fenômeno "nem nem" no Brasil é um dos elementos centrais da também estrutural resistência à queda dos indicadores de desigualdade econômica e social, o que abre os horizontes do combate à desigualdade para a inclusão desse fenômeno, estrutural e persistente, na agenda das políticas públicas e da pesquisa social por aqui.

\section{UM FENÔMENO ESTRU- TURAL}

Desdobremos os dados disponíveis para alguns países ricos segundo o sexo. O Gráfico 1 ilustra a evolução da proporção de homens e mulheres entre 15 e 29 anos de idade que não estavam nem estudando nem trabalhando nos 21 países da 
União Europeia, ${ }^{3}$ para o período 1997-2010, segundo faixas etárias. Chama a atenção a dessemelhança segundo o sexo, tanto nas proporções quanto no movimento das curvas temporais das diversas faixas etárias. As proporções de homens "nem nem" são sempre menores do que as de mulheres, e o impacto da crise de 2008 foi muito mais intenso no caso deles, que viram a taxa de exclusão da escola e do trabalho subir mais de 3 pontos percentuais nos dois anos posteriores ao estouro da bolha imobiliária norteamericana, contra 1 ponto percentual no caso delas.

Descendoaos detalhes, a linhamicropontilhada expressa o total da população analisada (15 a 29 anos) de cada sexo. Por ela vemos que, entre 1997 e 2008 a taxa de mulheres "nem nem" caiu quase constantemente (ficando estável entre 2003 e 2005), saindo de pouco mais de $20 \%$ para atingir $15 \%$ ao final do período de 12 anos, voltando a aumentar um ponto percentual de 2008 a 2010. O ano de 2008, pois, foi momento de inflexão num processo contínuo de redução do que eu denominarei aqui, provisoriamente, de "taxa nem nem de exclusão" das mulheres. Esse movimento pode ser explicado pela também contínua entrada delas no mercado de trabalho, processo cujas raízes remontam, na Europa, aos anos 1960, mas que, aparentemente, ainda não se completou. ${ }^{4}$ Note-se que a

${ }^{3}$ A OCDE inclui os países mais ricos, como os da União Europeia, Estados Unidos, Japão, Austrália e Canadá, além de países de renda média como México e Chile. A maior diversidade interna à OCDE justifica um olhar mais refinado nos países europeus, que, ademais, sofrem de maneira muito pronunciada os efeitos da crise de 2008 sobre o emprego dos jovens.

${ }^{4}$ Para análise de longo curso sobre o processo de inclusão das mulheres no mercado de trabalho na Europa como um todo, ver Crouch (1999) e também Costa (2000). A vasta literatura sobre o tema enumera uma série de explicações, concomitantes ou concorrentes segundo o caso, tais como a redução da taxa de fecundidade, dos encargos com filhos (assumidos pelos Estados de Bem estar, como creches e escolas), maior duração das licenças maternidade e paternidade (que reduzem a incompatibilidade entre ter filho e manter o emprego), mudanças de mentalidade quanto à divisão sexual do trabalho no mundo doméstico, mudanças na divisão social do trabalho por sexo, redução do emprego industrial e aumento do emprego nos serviços e comércio, políticas ativas de emprego em favor das mulheres, expansão de formas flexíveis e temporárias de emprego (como mostrado em OCDE, 2002), atraentes para mulheres com filhos e os desempregados, dentre as mais importantes. Para estudos comparativos mais recentes numa literatura sempre em expansão, ver Thevenon (2009) e, numa perspectiva econométrica, Cipellone et al (2012). queda mais intensa ocorreu junto às mulheres entre 25 e 29 anos, seguidas pelas de 20 a 24 . No primeiro grupo, boa parte, senão a maioria delas, já havia completado seus estudos. Logo, o que está sendo ilustrado é um processo constante de troca, pelas mulheres, de formas de inscrição social centradas no mundo doméstico, pelo mercado de trabalho. A queda na faixa de 20 a 24 anos também é expressiva (7 pontos percentuais até 2008) e denota o mesmo processo de incorporação ao mercado de trabalho, elemento menos presente na faixa etária mais jovem (15 a 19 anos), cujas proporções das que estavam na escola ainda eram muito altas. Na verdade, segundo a mesma fonte de dados, para essas adolescentes a redução da proporção de "nem nem" se deveu não à entrada no mercado de trabalho, mas, sobretudo, ao aumento da proporção que continuou estudando.

No caso dos jovens homens, os movimentos são menos intensos até 2008, e mais abruptos a partir de então. A linha micropontilhada (que ilustra toda a amostra de 15 a 29 anos) revela pequena variação em torno da média de $11 \%$ entre 1997 e 2004, caindo mais fortemente até 2008 para, então, crescer de forma importante até 2010, atingindo quase $14 \%$ de "nem nem". Tal como no caso das mulheres, as maiores taxas de exclusão do binômio escola-trabalho se deram na faixa de 20 a 24 anos e de 25 a 29 anos (ambas com crescimento de 5 pontos percentuais, ou mais, em apenas dois anos), e as proporções foram bem maiores no caso deles.

É importante notar que, tanto no caso dos homens quanto no das mulheres nessas faixas etárias, entre 2008 e 2010 aumentou um pouco a proporção dos que permaneciam na escola (com isso adiando sua entrada no mercado de trabalho), o que quer dizer que o aumento dos "nem nem" deveu-se, quase exclusivamente, ao desemprego de jovens antes ocupados, e que já tinham deixado a escola. E o processo é mais intenso para os homens do que para as mulheres. ${ }^{5}$

${ }^{5}$ A literatura econômica sobre a entrada das mulheres no mercado de trabalho tem chamado a atenção para o fato de que elas competem, sobretudo, com os homens mais jovens, com isso contribuindo para aumentar sua taxa de desemprego (Pissarides et al., 2003). 
Desse ponto de vista, parte do fenômeno midiaticamente tratado como novo, que estaria afetando de forma diferenciada uma geração específica, agora rotulada de "geração nem nem", na verdade é desemprego juvenil em larga escala, ocorrendo entre jovens que já haviam deixado a escola para trabalhar e que, diante da redução das perspectivas do mercado de trabalho, já não conseguem emprego, ou decidiram, ou estão em condições (tendo em vista as salvaguardas dos estados de bem estar na Europa ou as redes de proteção familiar) de esperar por uma ocupação num futuro melhor. ${ }^{6}$ Pequena parte dos afetados pela crise retomou os estudos, enquanto outra pequena parte dos que, de outro modo, teriam deixado a escola, decidiu permanecer nela, aspecto mais saliente entre as mulheres de 15 a 24 anos. Mas proporção elevada dos jovens europeus (mais de $18 \%$ dos jovens de 20 a 29 anos, valor que chegou a $22 \%$ na Grécia e $28 \%$ na Espanha em 2010, segundo a mesma fonte do Gráfico 1) simplesmente não tinha emprego para si, já tendo abandonado a escola. ${ }^{7}$

O mais importante a reter desses dados, contudo, é que estamos diante de um fenômeno estrutural, que atinge proporções relevantes de homens e mulheres jovens há muito tempo (portanto, devemos falar de gerações sucessivas de "nem nem"), tendo-se agravado depois de 2008, a ponto de provocar uma crise social de proporções continentais, colocando os jovens, uma vez mais, no centro da contestação à ordem econômica global $\mathrm{e}$ suas instituições de sustentação, nacionais e supranacionais. ${ }^{8} \mathrm{O}$ agravamento do fenômeno transformou-o de questão estrutural em problema

${ }^{6}$ Para os regimes mistos de bem estar na Europa e na América Latina, ver Dombois (2012).

${ }^{7}$ Estudo importante da condição "nem nem" no Japão é Brinton (2011). A autora mostra como a crise dos anos 1990 rompeu o padrão de transição de escola para o trabalho naquele país, principalmente, mas não exclusivamente, entre as classes mais baixas, tornando o termo NEET corrente na literatura dos anos 2000, algo impensável nos 20 anos anteriores.

${ }^{8}$ Os movimentos sociais contra a crise não são objeto desta análise, e, obviamente, não se restringiram aos protestos de jovens "nem nem". Mas não há dúvida de que sua energia contribuiu para radicalizar os movimentos. Ver, por exemplo, Givans e Soule (2011), os vários artigos em Gohn e Bringel (2013), além de Estanque et al. (2013). social e inflamou a disposição militante de jovens por todo o mundo desenvolvido.

É uma trivialidade sociológica afirmar que a entrada na vida adulta, enquanto realização de projetos de inscrição social e afirmação de identidades, não tem o mesmo significado para homens e mulheres. Mas o esquecimento dessa trivialidade pode levar a interpretações equivocadas, cegas em relação às diferenças de gênero. É preciso insistir, pois, que, no caso das mulheres, estar fora da escola e do trabalho não necessariamente denota frustração de expectativas ou desestruturação de projetos de vida, como pode ser o caso para a maioria dos homens, em especial os mais velhos entre os jovens. Uma proporção significativa delas estará, na verdade, realizando projetos de maternidade ou de casamento (em especial entre as mais velhas), com isso adiando sua entrada no mercado de trabalho, embora já tenham completado o ciclo escolar. Mas a proporção do fenômeno no continente europeu permite suspeitar que, também no caso delas, a crise afetou parte significativa das que tinham projetos de vida centrados no mundo do trabalho.

\section{GERAÇÕES “NEM NEM” NO BRASIL}

O Brasil viveu momento semelhante ao que se viu na Europa em anos recentes, tanto no que se refere ao desemprego juvenil quanto na proporção de "nem nem" na população mais jovem. Mas, aqui, os movimentos têm sido bem menos intensos. Em primeiro lugar, como na Europa, as mulheres vêm deixando cada vez mais a condição de "nem nem" rumo ao mercado de trabalho, mas em ritmo mais brando. Como mostra o Gráfico 2, em 1999, 30,5\% das jovens entre 15 e 29 anos (linha pontilhada superior do gráfico das mulheres) estavam nessa condição, proporção que atingiu pouco menos de $27 \%$ em 2008, subindo um ponto percentual daí a 2011. E, tal como no caso europeu, a queda mais acentuada ocorreu na faixa etária de 25 a 29 anos (queda de $40 \%$ para $33 \%$ de "nem nem”), portanto de mulheres entrando na maturi- 
Gráfico 2 - Proporção de jovens de 15 a 29 anos que não estudam nem trabalham, segundo sexo e faixas de idade, Brasil, 1999-2011
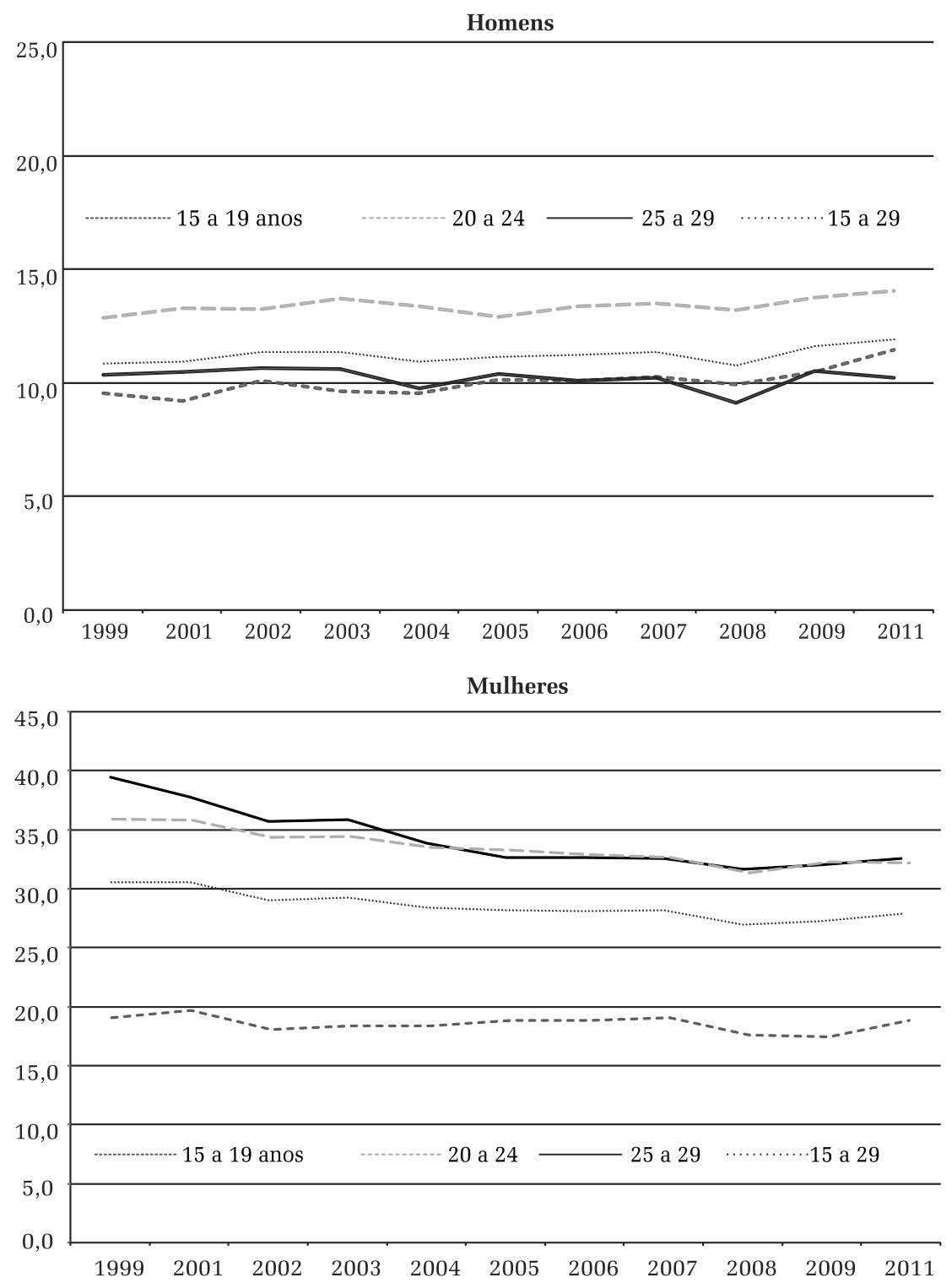

Fonte: PNAD, vários anos.

dade e que, mesmo estando em sua maioria já casadas ou com filhos (segundo a mesma fonte do gráfico), passaram a estar mais intensamente engajadas no mercado de trabalho (e estudando em menor proporção). Aqui, como na Europa, a redução da proporção de mulheres fora da escola e do mercado de trabalho expressa a crescente procura por inserção produtiva por parte delas, e não tanto o retorno à escola para retomada dos estudos. Ainda assim, a proporção de jovens mulhe- res "nem nem" no Brasil foi de pelo menos 13 pontos percentuais acima da média europeia ao longo do período.

Aqui, ao contrário da Europa, não podemos falar numa "geração nem nem”, ou de um grupo etário específica e intensamente afetado pela crise de 2008. A linha pontilhada do gráfico relativo aos homens de 15 a 29 anos deixa clara a pequena variação em torno da média de $11,2 \%$ (desvio padrão de apenas 0,3 pontos percentuais) de jovens excluídos do trabalho e da escola ao longo dos 12 anos retratados aqui. A partir de 2008, houve pequeno aumento na taxa, de $10,8 \%$ para $11,9 \%$, mas não a ponto de provocar uma "explosão” de exclusão capaz, por exemplo, de ser percebida como crítica. A inflexão observada ocorreu no interior da zona de variação (em torno da média) típica da década anterior. E, vale notar que esse comportamento médio, isto é, relativo a todo o grupo de 15 a 29 anos, se repetiu em cada faixa etária em particular, com possível exceção dos mais jovens entre eles (15 a 19 anos). Aqui, o desvio padrão foi um pouco maior ( 0,6 pontos percentuais), com crescimento de $10 \%$ para $11,4 \%$ na taxa "nem nem" de exclusão entre 2008 e 2011. Ainda assim, trata-se de crescimento longe de poder ser considerado explosivo, mesmo se imaginarmos que, nessa faixa etária, quando fora dos ambientes de sociali- 
zação secundária mais importantes (a escola e o local de trabalho), os jovens estão em posição mais vulnerável vis-à-vis o que se poderia denominar "os apelos do mundo", isto é, as redes sociais concorrentes que convocam constantemente seu engajamento. $^{9}$

O caso das mulheres é algo diverso, porque a queda na taxa "nem nem" de exclusão vinha ocorrendo de maneira lenta, mas contínua, queda que foi interrompida bruscamente em 2008. Ainda assim, a interrupção, aparentemente, não foi tal que tivesse potencial para gerar a percepção de que se estava vivendo uma crise social. ${ }^{10}$

Esse rápido quadro mostra que a faixa etária escolhida pela OCDE apresenta problemas analíticos importantes. Idades entre 15 e 29 anos expressam momentos biográficos muito distintos. Aos quinze anos, estar fora da escola é uma "anomalia” que diz muito sobre o sistema escolar, que deveria ser o destino de todos eles, ainda mais na nova configuração do Ensino Fundamental no Brasil, com duração de 9 anos ou séries. Aos 15 anos, a totalidade dos(as) jovens deveria estar estudando, de preferência na nona série (num currículo normal, sem atrasos ou repetência), enquanto outra parte poderia estar no primeiro ano do Ensino Médio. $^{11}$

Na outra ponta do espectro etário sugerido pela OCDE (que mantive para efeito desta comparação), os/as jovens de 29 anos, em princípio, já deram início à sua vida produtiva, e, ao contrário dos muito jovens, deles deve-se esperar que estejam procurando emprego ou trabalhando em sua maioria ou, no caso das mulheres, em parte viven-

${ }^{9}$ Refiro-me ao mundo do crime, ao ócio improdutivo, às redes sociais reais (as gangs, turmas e galeras) ou virtuais, e, também, o mundo religioso etc.

${ }^{10}$ Os movimentos coletivos de junho de 2013 no Brasil não parecem ter sido detonados pela crise de desemprego juvenil. O estopim da mobilização foi o Movimento pelo Passe Livre (MPL), uma organização estudantil, e, na infinidade de demandas difusas propostas pelos jovens nas ruas, não estava o fim do desemprego, como foi o caso na Europa, muito especialmente em Portugal e na Espanha.

${ }^{11} \mathrm{E}$, de fato, 92\% dos jovens daquela faixa etária estavam estudando em 2011, segundo a mesma fonte do Gráfico 2. Mas $8,3 \%$ dos homens e $7,8 \%$ das mulheres já não estavam na escola. E dois terços desses jovens tampouco estavam no mercado de trabalho, seja empregados ou procurando emprego. do projetos de construção familiar. ${ }^{12}$ Em todo caso, ainda que ter filho estivesse associado à maior proporção de mulheres adultas "nem nem", as que trabalhavam eram a maioria (62\% das mães e 76\% das que não tinham filho), e uma pequena proporção apenas estudava.

Isso recomenda parcimônia na delimitação do espectro etário relevante para a análise da condição “nem nem”. Abro, então, um parêntese para avaliar o problema com maior rigor.

\section{SOBRE JUVENTUDE E GERAÇÕES}

Num momento dado da biografia de uma pessoa (indivíduo de uma geração determinada), ela é o produto de sua trajetória, o resultado acabado, até aquele ponto, de suas escolhas e ações passadas ou, quando muito jovens, das escolhas, ações e omissões (mais ou menos restritas ou favorecidas pela classe social ou trajetória de vida) de seus pais ou responsáveis quanto a em que escola estudar, em que bairro morar, que atividades físicas ou artísticas desenvolver, que amigos favorecer ou evitar etc. Como ponto de chegada de biografia mais ou menos escolhida, mais ou menos vivida como resíduo das escolhas de outros, ou seu resultado, a pessoa é, também, um conjunto multidimensional de possibilidades, cuja finitude é função dos recursos socialmente disponíveis, disponibilidade que está, desde logo, desigualmente distribuída. As pessoas não nascem iguais em suas potencialidades e possibilidades. A desigualdade está inscrita no território de nascimento (campo ou cidade, cidade grande ou pequena, o Brasil ou a Suécia), na existência ou não de hospitais e condições adequadas de salubridade do local de nascimento, nos recursos financeiros e culturais das famílias, no acesso à saúde pré-natal da mãe e do bebê etc., e nada disso está igualmente distribuído. Isso é uma trivialidade sociológica, e serve apenas para deixar claro, desde

\footnotetext{
${ }^{12} \mathrm{Na}$ verdade, ter tido um filho impacta mais intensamente as mulheres mais jovens. Nada menos que $70 \%$ das mães de 15 anos eram "nem nem", taxa que caía a $35 \%$ no caso das mães que tinham 29 anos. Entre as mulheres sem filhos nesta faixa etária, a proporção de "nem nem" caía para $21 \%$.
} 
logo, que as pessoas não são potencialidades indeterminadas ao nascer. Seus caminhos possíveis configuram um conjunto de probabilidades de destino em etapas sucessivas da vida que apenas muito tardiamente são vividas pela pessoa como propriamente fruto de escolhas suas. ${ }^{13}$

Num momento determinado da vida, pois, a pessoa é o ponto de chegada de potencialidades desiguais no ponto de partida tornadas, na trajetória de vida, corpos desiguais, habilidades físicas e mentais desiguais, recursos socioeconômicos desiguais inscritos em redes institucionais e de interação que configuram capitais econômico, cultural e social desiguais. Toda pessoa, queira ou não, saiba disso ou não, traz consigo o seu passado. Mas ela é, também, um conjunto de potencialidades que não estão jamais inscritas inteiramente em seu passado como campo de determinações já realizadas em seu corpo e em sua mente. O que a pessoa é (na totalidade finita de suas determinações atuais em termos de recursos econômicos, habilidades cognitivas, disposições físicas, constituição emocional, preferências, projetos de vida e padrões éticos) nos permite tecer hipóteses bastante plausíveis sobre suas oportunidades de vida no futuro, mas essas hipóteses estão destinadas a ser negadas em boa parte. Isso porque a sociedade moderna é aberta até certo ponto, ${ }^{14}$ fluida até certo ponto, obviamente de maneira diversa para as diversas classes sociais, mas é indubitável que está em constante transformação, sendo esta uma característica definidora da modernidade (Giddens, 1991). Se o médio prazo está sendo parido nas entranhas do presente, e terá dele aquilo que, em toda sociedade, é acomodação de processos de história lenta (as mudanças populacionais, as transformações na estrutura produtiva, a configuração institucional do Estado, nela

\footnotetext{
${ }^{13}$ Bourdieu (2007[1979]) chamou a atenção para o caráter sistemático e de classe das probabilidades de trajetórias de vida. Uma crítica interna ao constructo bourdieusiano é Lahire (2001), que recusa a ideia de habitus como corporificação das trajetórias pessoais. Sua noção de disposições é mais próxima do que proponho aqui.

${ }^{14}$ É conhecida a formulação "tudo que é sólido desmancha no ar" de Marx no Manifesto Comunista, apropriada por Marshall Berman em seu livro de mesmo nome, no qual a modernidade é apresentada como uma era fáustica. O próprio Berman (1982) sugere que o faustianismo da modernidade bebe do sangue dos trabalhadores.
}

o sistema educacional etc.), permitindo, com isso, grande previsibilidade dos movimentos em grande escala, por outro lado, é muito difícil prever, com segurança, o destino de um indivíduo em particular e mesmo de comunidades inteiras. Quando as comunidades imaginadas que são as nações (Anderson, 1993) atingem certo patamar de renda e riqueza, o mundo de possibilidades e oportunidades abertas a seus membros deixa de ser um conjunto de impossibilidades ou barreiras à mobilidade ou à fruição dos recursos socialmente disponíveis, e isso para parcela crescente dos concidadãos. Isso porque o crescimento econômico, em toda parte, ganha a forma, dentre outras coisas, de recursos materiais e simbólicos públicos, mesmo quando destinados a favorecer a atividade econômica e a acumulação de capital. Rodovias, ferrovias, energia e os muitos serviços de comunicação são apenas alguns exemplos desses meios e recursos que, criados pela e para acumulação capitalista, melhoram as condições de vida de parcelas crescentes da população. A materialização desses recursos no território lhes dá durabilidade, e, uma vez materializados, eles mudam as probabilidades de percurso de grupos inteiros de indivíduos, com isso dificultando a construção de prognósticos plausíveis sobre sua vida no futuro.

O acesso a esses recursos é desigualmente distribuído, claro, e um dos marcadores centrais dessa desigualdade é, justamente, a idade. Mais ainda quando se miram os mercados de trabalho e escolar. Mudanças sociais ocorrendo num período específico não afetam da mesma maneira as diferentes gerações. Uma crise no mercado de trabalho que reduza de forma importante as chances de emprego dos mais jovens (como o que ocorre hoje na Europa e muito especialmente na Grécia e na Espanha) tem efeitos sobre todos, mas os jovens terão comprometidas suas chances de vida por muitos anos, provavelmente para o resto de suas vidas. ${ }^{15}$ Do mesmo modo, uma hecatombe nuclear

${ }^{15}$ A literatura sobre impactos de eventos de desemprego juvenil na vida produtiva posterior tem longa história na Europa, onde pesquisas longitudinais são comuns. Para comparações entre vários países, ver Russel e O’Connell (2001), Bradley e van Hoof (2005) e Wolbers (2007). Perspectivas de longo prazo são Steijn (2006), sobre a Holanda, e Vanttaja e Järvinen (2006) sobre a Finlândia. Ver ainda Shildrick e MacDonald (2007) sobre as trajetórias de exclusão dos mais pobres na Inglaterra. 
tem o mesmo efeito sobre a saúde de todos, mas o efeito é mais duradouro para os mais jovens, que precisarão construir suas vidas com um handicap sanitário que terá duração mais curta para os mais velhos, muitos deles já aposentados. As gerações chegadas ao sistema educacional num momento de universalização da oferta ou de melhoria generalizada de sua qualidade terão condições melhores de acesso a melhores posições no mercado de trabalho do que gerações imediatamente posteriores, ou eventualmente anteriores, que sofram com momentânea, mas duradoura (tendo em vista as janelas temporais de suas vidas) crise do ensino no futuro (por exemplo por desinvestimento, como ocorreu na Argentina nos anos 2000 e tende a ocorrer na Grécia e na Espanha hoje, fruto da falência dos estados de bem estar nos dois países). Guerras civis têm efeito semelhante, e assim por diante.

Além disso, as sociedades demarcam barreiras à entrada em dimensões institucionais que são, muitas vezes, em parte ou exclusivamente etárias: classificação etária de eventos culturais, por exemplo, com fronteiras rígidas (proibindo a entrada de menores de 18 anos - como nos cinemas ou casas noturnas) ou mais latas, mas, ainda assim, importantes, como a proibição do trabalho para menores de 14 ou 16 anos, dependendo do país, a obrigatoriedade de aposentadoria a certa idade etc. Se essas barreiras se aplicam a todos os membros de uma certa idade em qualquer tempo (desde que as regras não mudem), num momento dado do tempo é uma geração específica que as vivencia, aquela que tem 14 ou 16 anos ou a idade obrigatória de aposentadoria, por exemplo. No ano seguinte, serão outras pessoas etc., mas é um grupo específico de pessoas a cada vez que vive a mesma experiência e ao mesmo tempo. ${ }^{16}$

${ }^{16} \mathrm{O}$ problema das gerações frequenta a discussão sociológica de tempos em tempos, sem nunca deixar a cena teórica ou de pesquisa. Os trabalhos pioneiros são, obviamente, Ortega y Gasset (1987) e Manheim (1928), mas crises periódicas, que afetam gerações de jovens, colocam de novo o tema em evidência. Foi o caso com o movimento estudantil de 1968 no mundo e é o caso agora, na discussão da "geração nem nem". Para o maio de 1968, analisado do ponto de vista geracional, ver Eisenstadt (2002). Domingues (2002) é uma boa sistematização do debate teórico sobre o tema.
É nesse sentido que é possível falar-se numa geração "nem nem” em certos países europeus, um grupo etário que trará consigo uma marca coletiva e comum a todos os seus membros, de dificuldade ou impossibilidade de acesso ao sistema educacional e ao mercado de trabalho num momento crucial de suas trajetórias de vida.

Pois bem, avaliado contra esse pano de fundo, o espectro etário de 15 a 29 anos (utilizado pela OCDE no estudo apresentado mais acima) marca momentos muito distintos nas biografias dos jovens, suas potencialidades e possibilidades. Em termos substantivos, comparar um/a jovem "nem nem" de 15 anos com outro/a de 29 não faz sentido, já que boa parte das condições sociais e das possibilidades biográficas e identitárias dessas idades polares é, a rigor, incomensurável. Na seção anterior, utilizei a faixa de 15 a 29 anos porque o interesse era comparar com a situação na Europa, cujos dados foram tornados públicos quando eu iniciava a redação deste artigo. Agora, é preciso ser mais rigoroso na delimitação do escopo empírico da análise, se o que se tem em mente é compreender, de maneira adequada, a condição “nem nem” e formular uma agenda de pesquisas para o país, tendo em vista, sempre, determinações e potencialidades de trajetórias sociais que, de algum modo, permitam a realização de projetos virtuosos de inclusão social, isto é, longe das zonas de vulnerabilidade representadas por empregos precários, desemprego, ausência de proteção social etc.

Proponho como faixa etária de interesse para o estudo da condição juvenil "nem nem" como um problema social digno de se transformar em problema sociológico, aquela entre 18 e 25 anos. Sustento que, nessa faixa etária, faz sentido usar o termo "taxa nem nem de exclusão" como uma medida da vulnerabilidade social dos jovens, tendo em vista que:

1. Aos 18 anos a maioria dos jovens brasileiros já deixou ou está em vias de deixar o ensino médio. ${ }^{17}$ Como a taxa de transição para o ensino

${ }^{17}$ Ver Leão et al. (2011); Silva et al. (2012). Pesquisa quan-
titativa importante sobre as mudanças nos padrões de titativa importante sobre as mudanças nos padrões d
entrada no mercado de trabalho é Tomás et al. (2008). 
superior é historicamente baixa no país (Pinto, 2004; Comin e Barbosa, 2011, Torche e Ribeiro, 2012), deixar o ensino médio significa, para a maioria dos jovens, deixar o sistema escolar, mesmo que provisoriamente. ${ }^{18}$ No caso das mulheres, por exemplo, a proporção de "nem nem" saltou de $19 \%$ aos 17 anos para $30 \%$ aos $18 \mathrm{em}$ 2011 (segundo a PNAD), mantendo-se nesse patamar ou em nível levemente superior nas idades subsequentes. No caso dos homens, segundo a mesma fonte (PNAD), a proporção saltou de $11 \%$ para $18 \%$ entre os 17 e os 18 anos, caindo a partir daí até $11 \%$ aos 25 anos, taxa que se manteve nas idades subsequentes. Trata-se, pois, de idade (18 anos) marcadora do abandono da escola e da possível entrada no mercado de trabalho para boa parte dos jovens. Geradora, portanto, das tensões e inseguranças típicas das transições biográficas cruciais, e que resulta em frustração de expectativas de emprego para boa parte deles ou, ainda, de inserção precária e insegura no mercado de trabalho.

2. Aos 25 anos, as taxas de exclusão “nem nem” estão estáveis para homens e mulheres, em torno de 11\% no primeiro caso e de $32 \%$ no segundo. A idade parece perder influência a partir desse marcador biográfico. Isto é, parece plausível imaginar que, na explicação da condição “nem nem”, ganham relevância características multidimensionais, extraetárias, relativas ao ambiente social mais geral em que os jovens passam a circular.

Isto posto, voltemos à questão central que nos guia nesta investigação: o que explica as taxas "nem nem" de exclusão no Brasil? Por que, por aqui, elas não provocaram a mesma comoção que na Europa? Para oferecer respostas tentativas a essas perguntas e extrair delas elementos para uma agenda de pesquisas e políticas públicas, no que se segue, apresentarei dois modelos logísticos, tendo a condição "nem nem" de jovens de 18 a 25 anos como variável dependente para os anos 2000

${ }^{18}$ No Brasil, como se sabe, é grande a proporção de jovens que deixa os estudos para trabalhar ou ajudar a família e, depois, retomam sua formação escolar quando estão em condições de financiar a universidade, em geral privada. Ver Cardoso (2013), Ribeiro (2011), Comin e Barbosa (2011). e 2010 no Brasil. Os modelos foram construídos a partir dos dados dos Censos Demográficos realizados naqueles anos. Diferentemente do que foi feito até aqui, a condição "nem nem" será definida como a totalidade dos jovens de 18 a 25 anos que não estavam nem na escola nem no mercado de trabalho, quer dizer, não tinham um emprego e não estavam em busca de um. Na discussão anterior, incluí os que procuravam trabalho (ação que define um desempregado) porque o interesse era comparar com os dados disponíveis para a OCDE. Agora, interessa a condição "nem nem" purificada dos jovens que tinham, ao menos, a expectativa de um emprego, expectativa expressa nas ações que tomaram para conseguir um. Essa definição torna mais apropriado falar-se em "taxa nem nem de exclusão", já que os jovens deveriam estar na escola ou, se fora dela, ao menos procurando trabalho. Não estando nem numa nem noutra condição, estão, de fato, excluídos de duas das principais estruturas de socialização e construção de identidades sociais para pessoas nesse estágio de suas biografias.

\section{UM MODELO PARA EXPLICAR A CONDIÇÃO "NEM NEM"}

Partamos da conhecida formulação de Marx no 18 Brumário: as pessoas fazem sua própria história, mas "não a fazem sob circunstâncias de sua escolha e sim sob aquelas com que se defrontam diretamente, legadas e transmitas pelo passado" (Marx, 1978, p. 331). Essas circunstâncias estão materializadas na estrutura dos mercados de trabalho dos locais onde vivem; na rede de estruturas estatais de suporte à vida e à atividade econômica; no conjunto de recursos existentes no território onde as pessoas constroem sua trajetória de vida. Como já se sugeriu, tudo isso está desigualmente distribuído em termos geográficos. Um modelo de explicação das probabilidades de exclusão da escola e do mercado de trabalho deve ter em conta essas diferenças. Alguém pode ser "nem nem” não por escolha ou acaso, mas por morar num município desprovido de recursos econômi- 
cos e institucionais, isto é, escola ou emprego para todos os que queiram estudar ou trabalhar.

Isso delimita a hipótese central a se investigar: a condição "nem nem" é fruto tanto de escolhas e trajetórias individuais quanto de contextos nos quais as pessoas tomam suas decisões, sobre os quais elas têm pouca ou nenhuma capacidade de intervir diretamente, e que, por isso, funcionam como condicionantes mais gerais de suas oportunidades de vida. Uma pessoa pode escolher mudar de cidade ou estado (ou mesmo de país) para melhorar suas probabilidades futuras, mas, num momento dado, essas escolhas já se materializaram no que estou denominando aqui de "taxa nem nem de exclusão" e não podem ser mudadas pelo indivíduo isolado.

A segunda hipótese, derivada da anterior, sustenta que, no caso do Brasil, a persistência de taxas elevadas de jovens "nem nem” (que dá caráter estrutural a essa condição) vem sendo contrabalançada por mudanças na direção oposta às observadas na Europa. Por aqui, o contexto econômico era, em 2010, bastante mais favorável do que o de dez anos antes, com isso renovando os horizontes de expectativa dos jovens e tornando críveis as perspectivas de inclusão no futuro.

A Tabela 1 apresenta os dados agregados para o Brasil nos dois pontos no tempo, isto é, a distribuição da taxa "nem nem" de exclusão, que é, também, a variável dependente dos modelos propostos. A proporção total variou pouco, de perto de $21 \%$ para perto de $20 \%$ de "nem nem" em 10 anos. Estamos falando de 5,5 milhões de jovens em 2000 e 5,3 milhões em 2010. Essa aparente estabilidade esconde mudanças importantes segundo o sexo. Confirmando a tendência detectada nos dados da PNAD, a taxa "nem nem" de exclusão das mulheres caiu quase 4 pontos

Tabela 1 - Proporção de jovens homens e mulheres de 18 a 25 anos que eram "nem nem" nas datas dos censos demográficos. Brasil

\begin{tabular}{l|c|c|c|c}
\hline Ano & Homens & Mulheres & Total & N \\
\hline 2000 & 11,5 & 30,4 & 20,9 & 5.514 .606 \\
\hline 2010 & 13,1 & 26,0 & 19,5 & 5.329 .799 \\
\hline
\end{tabular}

Fonte: Censos Demográficos do IBGE percentuais, enquanto a dos homens cresceu 1,6 ponto. Havia 4 milhões de mulheres "nem nem" em 2000, e 3,5 milhões em 2010, enquanto eles subiram de 1,5 para 1,8 milhão de excluídos. Em 2000 , as mulheres representavam $72 \%$ do total dos “nem nem”. Em 2010, 66\%. A “taxa nem nem” de exclusão continua a ser muito mais alta entre as mulheres, mas a mudança detectada permite alimentar a hipótese de que o efeito das variáveis selecionadas não será o mesmo nos dois pontos no tempo, tanto pelo aumento da proporção de homens quanto pela queda das mulheres. Isso porque sabemos que homens e mulheres têm destinos sociais distintos quando deixam a escola, em grande parte condicionados pelas hierarquias socialmente construídas com base nas relações de gênero (Hirata, 2002). E, também, porque ocorreram muitas mudanças nos padrões familiares e comportamentais nos 10 anos que separam os dois recenseamentos, ${ }^{19}$ para não falar das mudanças econômicas discutidas mais abaixo.

A condição social de interesse é fruto de história, circunstâncias atuais e escolhas que não são adequadamente mensuradas nas pesquisas domiciliares. Qualidade do ambiente familiar, estrutura do mercado de trabalho, estrutura da oferta educacional, preferências pessoais ou projetos de vida, nada disso é coberto pelos censos demográficos. Tudo o que podemos fazer é construir medidas aproximadas a partir dos dados disponíveis, e tecer, a partir dessas aproximações, hipóteses sobre as condições subjacentes às práticas dos jovens (como a disposição para se mobilizarem ou não para mudar o destino coletivo de uma eventual "geração nem nem").

Um modelo multivariado apresenta muitas vantagens, porque permite mensurar o impacto independente de uma variável, num ambiente complexo em que múltiplos determinantes atuam ao mesmo tempo. O modelo proposto mescla indicadores de contexto (familiar e municipal) com indicadores de trajetória pessoal dos jovens de 18 a 25

${ }^{19}$ Extensa discussão sobre as mudanças na composição das famílias é encontrada em Alves e Cavenaghi (2012). E, ainda, em Leoni, Maia e Baltar (2010). 
anos. Trata-se, portanto, de modelo multinível, que opera com variáveis enquanto agregados construídos a partir das informações sobre os indivíduos, e com variáveis propriamente individuais. Três agregados foram construídos para dar suporte à hipótese de que diferentes contextos oferecem chances diversas de inserção social dos jovens:

1. Tamanho do município. Variável fruto do agregado dos moradores do município. Os municípios foram agrupados em faixas de tamanho, como se verá. Espera-se encontrar menos "nem nem" quanto maiores os municípios, na hipótese de que eles oferecem maiores oportunidades de emprego e, também, é a maior a oferta escolar;

2. Mercado de trabalho municipal. Foi construído um proxi da capacidade de o município oferecer empregos, composto da taxa de participação das pessoas de 10 anos ou mais na PEA, ou seja, a proporção de pessoas com essa idade que estava empregada ou procurando emprego. A variável assume o mesmo valor para todos os moradores do mesmo município. Logo, ela distingue não as pessoas, mas os próprios municípios, uns em relação aos outros, como ambientes em que se gera ou não empregos. Para tornar-se operacionalizável e comparável nos dois pontos no tempo, transformei a distribuição em decis. Em 2000, os primeiros 10\% tinham taxa de participação na PEA de até 39,09\%, enquanto os $10 \%$ de maior participação tinham taxa de $60,79 \%$ ou mais. Em 2010, os números eram superiores a esses $(47,61 \%$ e $64,67 \%$ respectivamente), como era de se esperar, já que foi um ano de boom econômico e de geração de empregos, o que contribuiu para elevar a taxa de participação, sobretudo das mulheres. A hipótese, aqui, é a de que, quanto maior a taxa de participação na PEA, menor a proporção de "nem nem" na população mais jovem.

3. Oferta escolar municipal. Trata-se, também, de um proxi. Definiu-se como indicador aproximado da existência de uma rede municipal de ensino a proporção de pessoas com idade entre 7 e 17 anos que estava fora da escola no município. Evitou-se incluir jovens de 18 anos porque essa faixa etária define a população de interesse (jovens de 18 a 25 anos), o que geraria um problema de autocorrelação. Aqui, também, a variável assume o mesmo valor para todos os moradores, distinguindo, portanto, os municípios em sua capacidade de manter os jovens na escola antes dos 18 anos. A variável também foi transformada em decis de sua distribuição, pelas mesmas razões da variável anterior. A hipótese a se testar é a de que quanto mais jovens estejam fora da escola num município (expressão da baixa capacidade de investimento municipal), maior a chance de que um jovem de 18 a 25 anos seja "nem nem".

4. Região do país. Ainda como tentativa de controle das diferenças geográficas, incluí a região do país no modelo. Explorações iniciais do problema mostraram que as regióes Norte e Nordeste apresentam as maiores taxas "nem nem" de exclusão, e a região Sul, as menores.

5. Mora na cidade. Esse indicador complementa aquele sobre tamanho do município, ao distinguir os que moram na cidade e no campo. A hipótese é que o campo terá menor proporção de "nem nem" do que a cidade, tendo em vista a tradição brasileira de trabalho precoce no mundo rural.

Os indicadores de contexto familiar são, em boa parte, oferecidos pelos censos demográficos, alguns sendo perguntados diretamente (como a renda e o número de moradores do domicílio), outros sendo construídos depois pelo IBGE. Além dessas, criei outras para dar mais substância à hipótese da importância da família nas decisões e oportunidades dos jovens.

6. Renda familiar per capita. Utilizei a informação que veio originalmente nos censos, transformando-a em decis de sua distribuição, também para facilitar a comparabilidade. A hipótese é a de que quanto mais pobres as famílias, maior a taxa "nem nem" de exclusão, já que é potencialmente menor a capacidade das famílias sustentarem seus filhos na escola, menor a escolaridade média destes e menores as chances de emprego, dada a baixa qualificação. 
7. Tamanho da família. O número de membros da família não terá impacto direto, supõe-se, mas pela mediação da renda (de modo que famílias grandes com renda baixa terão chances diversas de famílias grandes com renda alta) e das condições estruturais dos municípios. Ainda assim, quis-se averiguar se essa variável tem impacto independente desses outros determinantes e em que direção.

8. Número de filhos de 4 anos ou menos na família. Essa é uma variável típica dos estudos sobre determinantes da renda pessoal ou da participação no mercado de trabalho. A hipótese é que um filho pequeno na família aumenta as chances de jovens mulheres deixarem os estudos e o trabalho (seja porque são as mães dessas crianças, seja porque são instadas a cuidar das crianças da família enquanto os adultos trabalham).

9. Há outro "nem nem” na família. Essa variável foi incluída na suposição bastante plausível de que, se há um jovem na família em condição vulnerável, haverá outros na mesma condição. A variável apresenta dificuldades, já que a pessoa que é "nem nem” está contida em sua definição, isto é, onde há dois “nem nem”, há, necessariamente, um. Ao transformar a informação numa característica familiar, o problema é, em parte, solucionado, sobretudo num modelo multivariado em que outras variáveis familiares ou contextuais estão em operação. É um problema de colinearidade, mas decidi pagar o "preço estatístico" para ganhar em compreensão do problema como algo que parece estar para além dos próprios indivíduos, embora seja vivenciado por eles. Além dessas variáveis de contexto, geradas secundariamente a partir das informações sobre as pessoas, o modelo inclui indicadores individuais sobre os jovens, suas características inatas e aspectos de sua trajetória pessoal. Já vimos que as probabilidades de se estar na condição "nem nem” são diversas segundo o sexo e a idade. Mas há outras dimensões relevantes disponíveis nos censos demográficos.

10. Sexo. O modelo toma as mulheres como referência, isto é, mede o efeito de ser homem na probabilidade de ser "nem nem”, por compara- ção com ser mulher. Espera-se efeito negativo (redução da probabilidade), já que esse resultado já foi apresentado na Tabela 1.

11. Cor. Agregou-se a informação dos censos numa dummy distinguindo brancos e não brancos. Os não brancos são a referência da regressão. Sigo, aqui, a sugestão de Hasenbalg e Silva (2003), que mostraram que as probabilidades de pretos, indígenas e pardos distam consistentemente das de brancos e amarelos, e são muito próximas entre si, tendo em vista o acesso à renda, à educação e ao mercado de trabalho. ${ }^{20}$

12. Escolaridade. Trata-se de outra dummy agrupando os que tinham escolaridade menor do que ensino fundamental completo (8 anos ou menos), e a referência na regressão são os com mais escolaridade do que isso. Espera-se que os menos escolarizados sejam "nem nem” em maior proporção, já que, tendo 18 anos ou mais, é grande a probabilidade de que estejam fora da escola. Com baixa qualificação formal, terão, por hipótese, maior chance de estar também fora de um emprego.

13. Tem uma restrição física grave. Trata-se de uma dummy que indica se a pessoa tem dificuldade permanente de enxergar, ouvir, caminhar ou tem uma doença mental. Supõe-se que qualquer dessas dificuldades impõe restrições à atividade escolar ou de trabalho.

14. Mulher com filho. Outra dummy, agora distinguindo as que têm e não têm filho. É sabido que os filhos são os principais determinantes da saída das mulheres do mercado de trabalho, e sabemos, pelos dados do próprio censo, que eles afetam, também, a frequência à escola.

15. Vive com os pais ou padrastos. Supõe-se que jovens vivendo em família têm maior probabilidade de permanecer estudando, reduzindo as chances de que sejam nem nem.

16. Tem ou teve cônjuge. A vida conjugal, presente ou passada, é outro determinante importante das chances das mulheres (e em menor parte dos homens), resultando, frequentemente, no abandono da escola e do trabalho.

17. Morou em outro município além do atual. A ${ }^{20}$ Ver também Cardoso (2013: cap 3). 
migração dos jovens, para acompanhar os pais ou por si mesmos, em geral se acompanha de incerteza quanto à inserção escolar e por vezes empregatícia. Procurou-se mensurar o efeito de ter migrado, ainda que sem o controle do período em que essa migração ocorreu, e espera-se que ele seja positivo, quer dizer, aumente a probabilidade de ser "nem nem".

18. Idade. Vimos que a probabilidade de ser "nem nem" varia com a idade, e pretende-se medir a direção do efeito independente desse indicador.

\section{DISCUSSÃO}

Os modelos para os anos 2000 e 2010 são apresentados na Tabela 2. Ela traz os efeitos líquidos de cada indicador, isto é, tem-se o quanto a probabilidade de ser "nem nem" aumenta ou diminui quando a condição ocorre, por comparação com a categoria escolhida como referência em cada variável, mantidos constantes os efeitos de todos os outros indicadores. Com exceção do número de componentes do domicílio e do número de crianças com 4 anos ou menos, todas as variáveis de interesse foram transformadas em dummies (assumem o valor 0 ou 1), e o efeito de cada categoria de uma variável se mede em relação à probabilidade da categoria de referência. Por exemplo, no caso da renda familiar, se o jovem morava numa família entre as $10 \%$ mais pobres em 2000 , a probabilidade de ser "nem nem" era 232,9\% maior do que a de um jovem de família entre as $10 \%$ mais ricas, categoria de referência selecionada no modelo, mantida constante (pela média) a probabilidade de ser "nem nem" em todas as outras variáveis. Em 2010, essa probabilidade havia saltado para 797,5\%.

Com exceção dos indicadores marcados com $\left.{ }^{* *}\right)$, todos os outros são estatisticamente significativos em pelo menos 0,01 , a maioria superior a 0,001 , sendo, portanto, muito robustos. Além disso, os modelos apresentam falsos $\mathrm{R}^{2}$ de $0,39 \mathrm{em}$ 2000 e 0,36 em 2010 , indicando que $36 \%$ ou mais da variância da taxa "nem nem" de exclusão são explicados por eles.
Os modelos confirmam a hipótese geral sobre os efeitos de contexto e trajetória, e, com poucas exceções, as hipóteses específicas sobre os efeitos de cada indicador também se confirmam. E houve mudanças importantes no impacto independente de cada indicador, entre 2000 e 2010, tendo em vista as profundas transformações por que passou o país no período. Desçamos, então, a alguns detalhes desse quadro geral.

Os contextos familiar e municipal se mostraram preditores poderosos das taxas "nem nem" de exclusão. Tomando-se o tamanho da família, cada novo membro adicionado reduzia entre 8 a $11 \%$ as chances de um jovem de 18 a 25 anos ser "nem nem" em 2000 e 2010. Vale marcar que a redução é contraintuitiva, já que a proporção de "nem nem" é sempre maior quanto maior o grupo doméstico, quando se trabalha com essa variável fora do modelo. ${ }^{21}$ Isso significa, como sugerido, que o efeito do tamanho da família se dá pela mediação de outros indicadores. E, de fato, se ajustamos o modelo passo a passo, adicionando uma variável de contexto por vez, o efeito do tamanho da família é sempre positivo até a inclusão da renda. É o controle pela renda familiar que inverte o sinal. Ou seja, o contexto familiar, de fato, configura-se como um campo onde interagem diversas dimensões, e não faz sentido tratar cada variável individualmente, sendo a renda a dimensão mais importante, mediadora dos demais indicadores.

O número de crianças de 4 anos ou menos no domicílio também mostrou-se relevante, com cada criança a mais reduzindo, em quase $10 \%$, a probabilidade de um jovem "nem nem" na família. A queda do impacto desse indicador entre 2000 e 2010 ocorreu no interior do intervalo de confiança dos parâmetros, portanto, não é significativa em termos estatísticos. Seria de se esperar mudanças mais pronunciadas, tendo em vista, por exemplo, que, em 2000, 2,6\% das famílias tinham um neto ou bisneto residindo no domicílio. Em 2010, a proporção subira para $4,8 \%$. Isto é, havia au-

${ }^{21}$ Uma regressão linear, contendo apenas a proporção de "nem nem" segundo o número de membros da família, gera um R2 de 0,899 em 2010, com cada membro a mais gerando um aumento médio de $4,3 \%$ naquela proporção. 
Tabela 2 - Modelo logístico de explicação da "taxa nem nem de exclusão" de jovens de 18 a 25 anos. Efeitos líquidos $^{* *}$ (em \%) sobre a probabilidade de estar fora da escola e fora do mercado de trabalho (não trabalha nem procura emprego). Brasil, 2000 e 2010

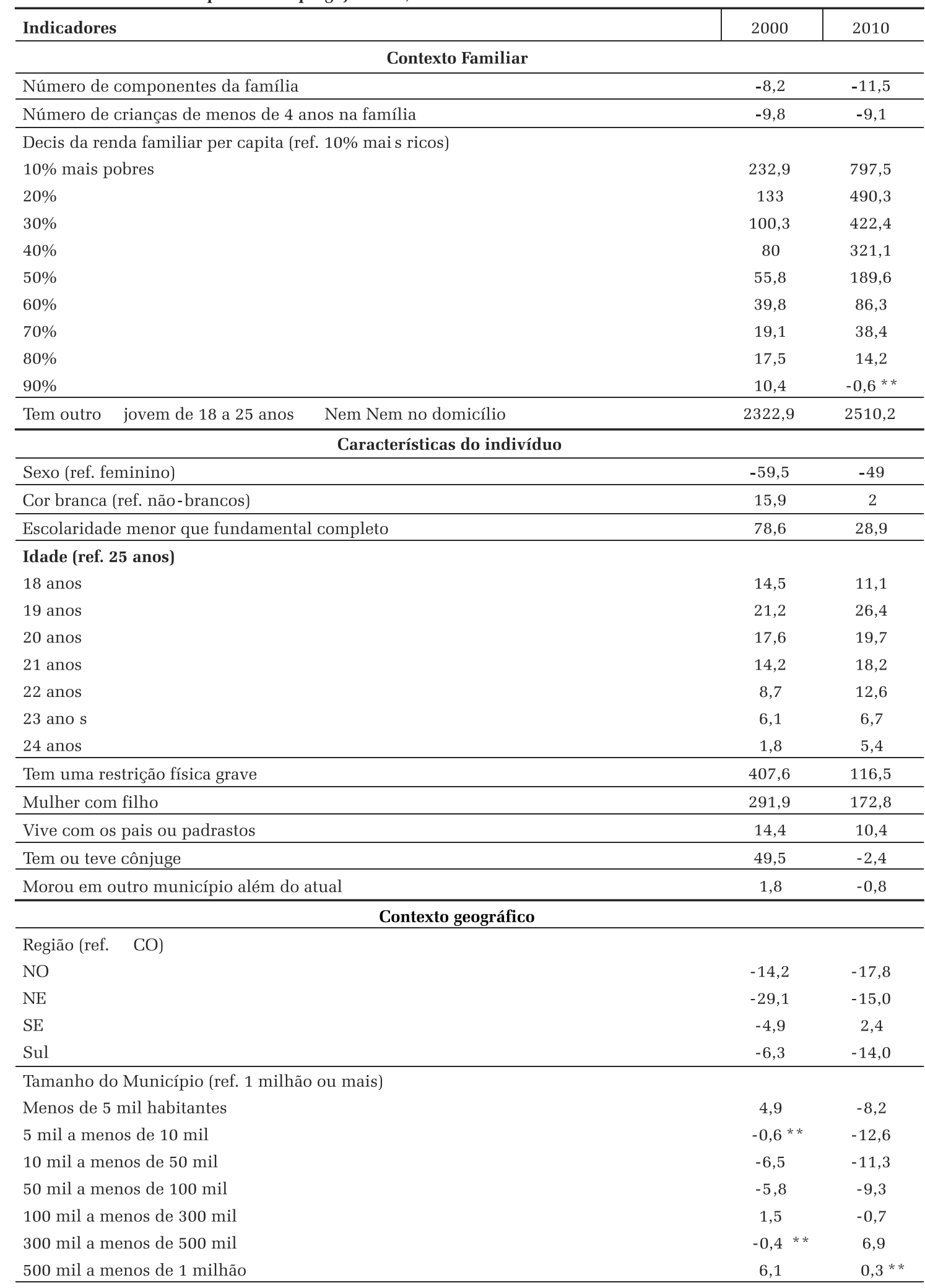


(Continuação)

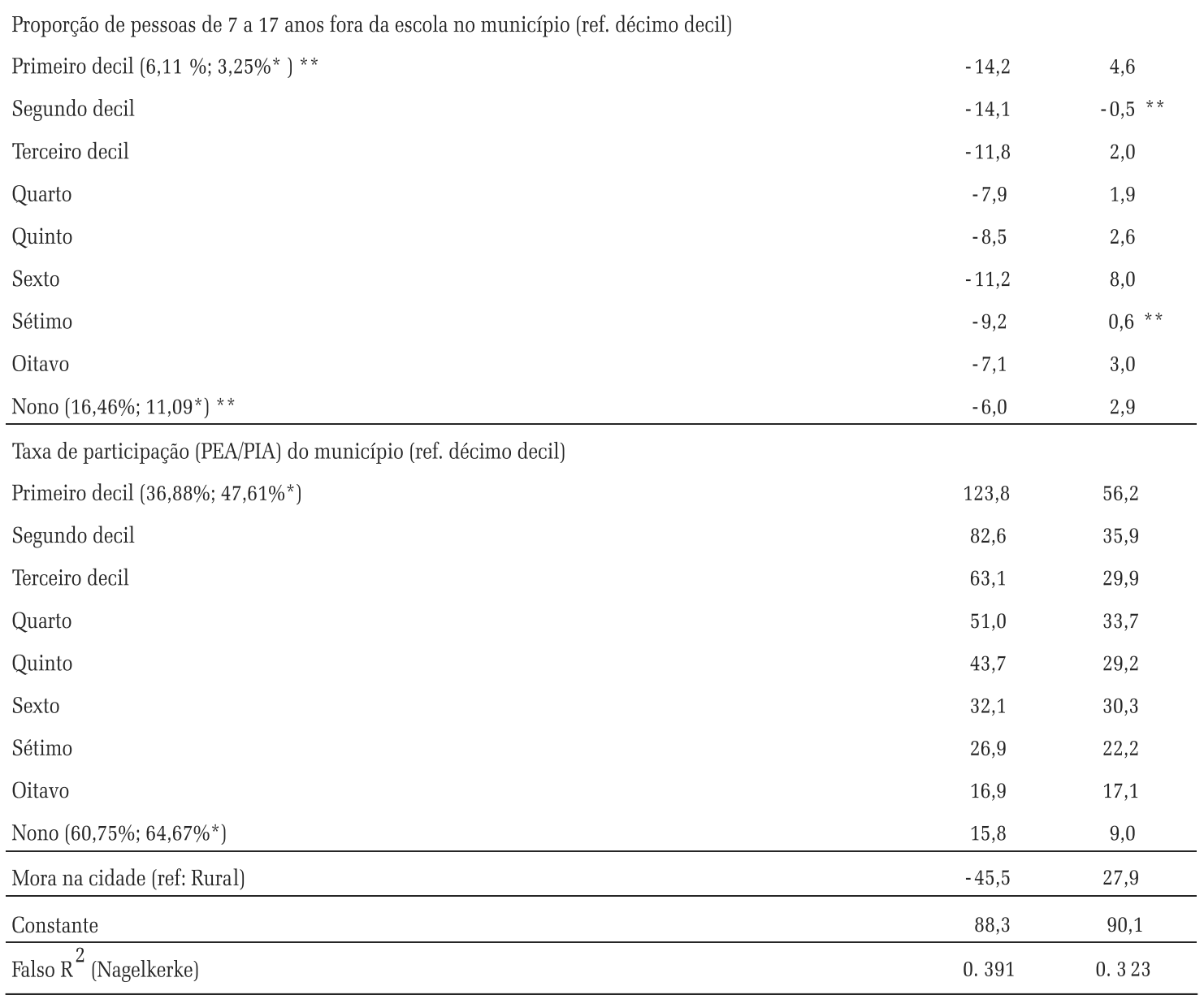

Fonte: Microdados dos Censos Demográficos de 2000 e 2010.

* Primeira proporção $=2000$, segunda $=2010$

** Todos os parâmetros significativos pelo menos em 0,01 exceto

*** Efeitos líquidos: antilog do parâmetro (B) ajustado pelo modelo.

mentado a proporção de convivência de mais de uma geração no mesmo espaço doméstico, com filhas (e filhos em menor medida) morando com os pais, sendo elas mesmas mães precoces. Mas essa mudança não aumentou o efeito independente de ter criança em casa. E, como no caso do número de membros da família, é a mediação da renda familiar que inverte o sinal do efeito, de outro modo positivo. Isto é, famílias mais ricas com crianças têm menor probabilidade de ter um jovem "nem nem" do que famílias pobres com crianças. Volto a isso na conclusão.

E, como esperado, a inclusão do indicador "tem outro nem nem na família” mostrou-se es- sencial na construção do contexto familiar. O parâmetro está enviesado, já que há um problema de colinearidade (o indicador "tem outro jovem nem nem no domicílio" contém a variável dependente), e é o que explica o elevado impacto independente dessa variável. Mas ela é teoricamente relevante, além de empiricamente consistente: em 2010, por exemplo, nas famílias com mais de um jovem com idade entre 18 e 25 anos de idade, se um deles era "nem nem", a chance de que o segundo também fosse era de espantosos $32 \%$, segundo o mesmo censo demográfico. Havendo um segundo "nem nem" nas famílias, com três ou mais jovens da mesma idade, a chance de haver um 
terceiro era ainda maior, de $41 \%$ (em 2000 as proporções eram de $21 \%$ e $32 \%$ respectivamente). Logo, haver um "nem nem" na família é um preditor poderoso das chances de haver outro, sendo a condição "nem nem" um indicador da vulnerabilidade diferencial das famílias.

O mais importante a reter nessa dimensão é que os efeitos das variáveis contextuais foram muito semelhantes nas duas pontas do tempo, com exceção da renda. Sabemos, pela literatura já citada, que as famílias passaram por mudanças importantes em sua estrutura no período, com aumento de famílias unipessoais, famílias conviventes, mães solteiras, homens vivendo sozinhos, famílias homoafetivas, etc. Mas os efeitos dos indicadores de morfologia da família se mantiveram quase constantes. A mudança mais importante ocorreu no impacto da renda familiar, com crescimento substancial do risco entre as famílias mais pobres em 10 anos. Em 2000, famílias entreas $10 \%$ mais pobres tinham $233 \%$ mais chances de ter um "nem nem" entre os seus do que famílias entre os 10\% mais ricos. Em 2010, esse valor havia aumentado para quase $800 \%$. Isto é, a disponibilidade de recursos familiares, tal como expressa pela renda enquanto capacidade de aquisição de bens como saúde e educação para seus membros, por exemplo, confere um caráter de classe às mudanças ocorridas no período, com aumento da vulnerabilidade dos mais pobres. Isto é, é maior a proporção de "nem nem" em 2010 entre as famílias que, em termos relativos, tinham menores condições materiais de dar respaldo a eles.

Na outra ponta, o contexto extrafamiliar também se mostrou relevante, mas em menor proporção do que a família. Os indicadores selecionados de infraestrutura municipal são quase todos estatisticamente significativos, mas apenas o indicador de robustez do mercado de trabalho local (taxa de participação de pessoas de 10 anos ou mais na PEA) tem incidência incontestável, ainda que tenha perdido intensidade entre 2000 e 2010. Essa perda parece estar associada à melhoria nas condições dos mercados de trabalho municipais, já que cresceu de forma importante a taxa de participação no tempo. Por exemplo, o valor de corte do pri- meiro decil foi de perto de $37 \%$ em 2000, subindo para quase $48 \%$ em 2010. A diferença entre o primeiro e o nono valor de corte foi de 24 pontos percentuais no primeiro ano, caindo para 17 pontos em 2010. Ou seja, a desigualdade entre os mercados de trabalho municipais foi reduzida de maneira importante, muito em função do aumento da taxa de participação das mulheres (Nonato et al., 2012), e isso explica boa parte da perda de intensidade do efeito da variável. Ainda assim, morar num município no primeiro decil de taxa de participação, aumentava em $56 \%$ a chance de um jovem ser "nem nem" em 2010, em comparação com um município no topo da distribuição (65\% ou mais de pessoas na PEA).

Perdeu intensidade, também, o indicador de investimento municipal na rede escolar, e pela mesma razão, isto é, houve melhoria nas condições de escolaridade da maioria dos municípios brasileiros, com isso reduzindo a desigualdade entre eles e, por conseguinte, o efeito diferencial nas chances de um jovem ser "nem nem". Em 2000, o valor de corte do primeiro decil foi de 6,11\% de jovens entre 7 e 17 anos fora da escola, proporção que caiu para 3,25 em 2010 (queda de 2,86 pontos percentuais). No topo (nono decil), a queda foi mais intensa, de 5,37 pontos percentuais (os valores estão entre parênteses na tabela). Isso aproximou as características municipais, reduzindo o impacto independente dessa variável.

Os demais indicadores de contexto têm efeito mais brando sobre as taxas "nem nem" de exclusão. Morar na Região Sul tornou-se um pouco mais vantajoso em 2010, por comparação com 2000, e no Nordeste, um pouco menos. O sinal do efeito de se morar no Sudeste mudou de negativo para positivo, mas numa faixa muito pequena de variação. O tamanho do município, por sua vez, ganhou maior relevância no tempo, com os menores municípios apresentando condições mais vantajosas em 2010 do que os maiores, por comparação com 2000. Isso também deve ser creditado à melhoria geral das condições dos mercados de trabalho no interior do Brasil, como vem mostrando a literatura especializada (IBGE 2012). 
A terceira dimensão de interesse é a trajetória individual, que, no censo demográfico, é apreendida a partir de uma série de indicadores sobre as características atuais das pessoas, boa parte delas fruto de escolhas, decisões e ações passadas. $\mathrm{O}$ ponto mais importante a se salientar é que, com exceção da idade dos jovens, todos os outros indicadores de trajetória perderam intensidade no tempo, ainda que permaneçam estatisticamente significativos. Ter uma restrição física grave, por exemplo, aumentava a chance de um jovem ser "nem nem" em 407,6\% em 2000, por comparação com os que não tinham uma restrição. $\mathrm{O}$ efeito foi reduzido a menos de $117 \%$ em 2010. Efeito ainda importante, claro, mas a queda estará, com certeza, associada ao impacto das políticas de ação afirmativa para portadores de necessidades especiais, que obrigam empresas a contratá-los numa proporção de sua força de trabalho e as escolas a desenvolverem mecanismos de inclusão de deficientes visuais, auditivos ou físicos. A adaptação das escolas para cadeirantes e o aumento da acessibilidade no espaço urbano são políticas com efeitos semelhantes: reduzir as restrições de acesso dessas pessoas aos espaços da escola e do trabalho. A persistência do efeito na casa dos $117 \%$ é indicador de que se está muito longe de universalizar a acessibilidade, e esse é, certamente, um tema importante para uma agenda de pesquisas e políticas públicas de desenvolvimento que tenha no horizonte a emancipação da maioria.

A redução do efeito da cor deve ser creditada ao mesmo processo de mudança nas relações sociais no país, fruto de políticas públicas e de redução da desigualdade daí decorrente. As políticas de ação afirmativa para negros estão longe de resolver o problema secular que é a persistência e reprodução da desigualdade racial, mas parecem estar reduzindo a distância entre os jovens no que respeita às chances de serem "nem nem". Os brancos tinham quase $16 \%$ de chances de estarem nessa condição, por comparação com os não brancos (tudo o mais permanecendo constante), efeito que caíra a 2\% em 2010. Lembre-se: está-se falando do efeito, independente da cor, num ambiente em que várias outras dimensões atuam ao mesmo tempo. Logo, a cor não-branca, que, tomada individualmente, aumenta a probabilidade de um jovem ser "nem nem", por outro lado, quando controlada pelos efeitos de contexto, inverte o sinal. Ainda assim, o que importa para nossa discussão é que a cor perdeu intensidade no tempo como componente explicativo da probabilidade de um jovem ser "nem nem".

Os filhos, como previsto, aumentam muito a probabilidade de as mulheres jovens serem "nem nem”, embora, como no caso das variáveis anteriores, tenha havido queda no efeito desse indicador no tempo. Em 2000, ter filho aumentava em $300 \%$ a chance de uma mulher jovem ser "nem nem", por comparação com as que não tinham. Em 2010, a probabilidade caíra para pouco mais de $170 \%$. A queda é importante e indica redução do peso dos filhos como elemento de ruptura nas trajetórias escolar e empregatícia das mulheres, o que pode estar associado à melhoria das condições econômicas de suas famílias (que permitem acesso a creches privadas), aumento da oferta de creches públicas ou escolas maternais etc. Retomo o ponto na conclusão.

Viver ou ter vivido com um cônjuge perdeu muito de seu impacto de um ano ao outro. O casamento (efêmero ou duradouro) tem, historicamente, maior efeito de ruptura para as mulheres do que para os homens. Esse efeito vem caindo, com o tempo, para as faixas etárias mais velhas entre os jovens. Mulheres casadas estão mais inseridas no mercado de trabalho hoje do que em 2000, fruto do processo já mencionado de transformação (embora lenta) das relações de gênero. E homens jovens experimentam relações conjugais precoces mais intensamente hoje do que há dez anos, ainda que não duradouras. A conjugação desses vetores de mudança deve estar contribuindo para explicar boa parte da anulação do efeito dessa variável entre os dois censos demográficos.

Por fim, e ao contrário do que seria de se esperar, viver com os pais ou padrastos aumenta as chances de o jovem ser "nem nem", por comparação com os que não vivem. Aqui, também, o efeito da variável se dá mediado por outros indicadores 
da família, sobretudo a renda. Isso porque, tomado isoladamente (fora do modelo), há mais jovens "nem nem" entre os que não estão morando com os pais do que entre os que vivem em família. Ao se controlar pela renda familiar, porém, o efeito muda de sinal, sugerindo que morar com os pais reduz o risco de ser "nem nem" apenas em determinadas condições de bem estar econômico familiar. Como há mais "nem nem” nas famílias mais pobres, morar com os pais, nessas condições, aumenta a chance de ser "nem nem". É o que explica a mudança de sinal, ainda que a uma taxa não muito alta (em torno de 10\%).

\section{CONCLUSÃO}

A condição "nem nem" dos jovens é um problema social de monta. Na Europa, ela adquiriu proporções explosivas, em parte por ter afetado diretamente jovens de classe média, que viram ruir seus projetos de inserção social em condições equivalentes ou melhores do que a de seus pais. A condição "nem nem" é um problema geracional e de classe por lá, e é vivida, em parte, como traição das promessas de emancipação pelo mercado, tendo, portanto, a forma da luta contra o neoliberalismo. ${ }^{22}$ No Brasil, a recorrência no tempo da taxa "nem nem" de exclusão (que lhe confere um caráter estrutural) não produziu os mesmos protestos que na Europa, em parte porque ela afeta mais as classes subalternas e as famílias mais pobres. Eé exatamente por essa razão que o país não pode considerar normal ou aceitável que um em cada dez de seus jovens do sexo masculino entre 18 e 25 anos esteja fora da escola e do mercado de trabalho. Essa proporção não é homogeneamente distribuída no território, sendo muito pior nas regiões e municípios mais pobres do país e, mais ainda, nas famílias de baixa renda. Isto é, a taxa "nem nem" de exclusão é maior nas regiões e famílias mais vulneráveis, e, nesse sentido, deve ser

${ }^{22}$ Ver os importantes artigos sobre os novos movimento sociais em Gohn e Bringel (2013) e também Estanque e al. (2013). tratada como um dos elementos centrais dessa vulnerabilidade. Isso quer dizer que o país está transmitindo a vulnerabilidade de uma geração a outra em proporção significativa. A taxa "nem nem" de exclusão, por ser estrutural e muito resistente à queda, configura-se, então, como um dos elementos estruturantes da persistência das desigualdades entre nós. Proporções sempre altas de jovens (que variaram pouco em torno da média de $11 \%$ no caso dos homens nos últimos 15 anos e, mais ainda, no caso das mulheres) carregarão para o resto de suas vidas o peso de ter deixado cedo a escola, com isso reduzindo suas chances no mercado de trabalho.

O problema é importante, também, no caso das mulheres. Mesmo que parte significativa delas seja "nem nem" porque constituiu família, a instabilidade dos laços afetivos no mundo contemporâneo torna mais do que provável a tentativa de retorno delas seja ao mercado de trabalho, seja à escola, caso os casamentos por ventura se desfaçam. A instabilidade dos vínculos empregatícios dos maridos menos qualificados também pode levar a que elas procurem inserção ocupacional no futuro, e isso se fará em condições de desvantagem vis-à-vis aquelas de sua geração que se qualificaram. Essa circunstância torna mais resistentes à queda as desigualdades de gênero no mercado de trabalho e, também, as desigualdades de renda para mulheres de uma mesma geração. A taxa "nem nem" de exclusão, pois, é um dos mecanismos recônditos da persistência secular das desigualdades no Brasil. Atacar a condição "nem nem" é atacar, insisto, um mecanismo gerador de exclusão e desigualdade a longo prazo.

Os modelos ajustados para a explicação das taxas "nem nem" de exclusão, e as mudanças encontradas nos dois pontos no tempo sugerem elementos para uma agenda de pesquisas e políticas públicas de desenvolvimento. O crescimento econômico e o maior acesso à renda têm efeitos multiplicadores importantes num país em que os serviços públicos de melhor qualidade são mercantilizados, como é o caso do Brasil. Há educação e saúde públicas, mas o acesso a elas tem nítido corte de classe, já que os serviços são consi- 
derados de má qualidade. A melhoria na renda leva as famílias a procurar serviços melhores no mercado (escolas privadas, incluindo creches, planos privados de saúde, automóvel em lugar do transporte público etc.), com isso reduzindo, em parte, o peso das desigualdades de acesso à infraestrutura urbana. $\mathrm{O}$ adensamento da malha escolar pública e sua extensão a novas áreas geográficas no interior das regiões mais pobres do país tem o mesmo efeito redutor de desigualdades regionais, abstraindo-se, para efeitos dessa discussão, a qualidade dos serviços ofertados.

O fato de as taxas "nem nem" de exclusão serem muito mais altas nas famílias de baixa renda revela a importância das políticas de distribuição de renda, sejam os programas de transferência condicional (tipo bolsa família), seja a política de valorização do salário mínimo. Essas políticas miram o curto prazo, isto é, dar acesso imediato ao mundo dos serviços públicos que as décadas de desinvestimento estatal acabaram transferindo ao mercado. No longo prazo, a melhoria dos serviços públicos oferecidos pelo Estado, decorrente do aumento do investimento hoje em curso, ${ }^{23}$ tornará menos relevante, espera-se, esse aspecto mercantilizado das relações sociais, reduzindo, ainda mais, as desigualdades que sustentam as diferentes probabilidades de um jovem ser "nem nem". Nesse sentido, estão corretos os que insistem no caráter estratégico de uma educação pública e universal de qualidade.

Políticas de estímulo à manutenção dos jovens mais pobres na escola, a partir dos 18 anos, também são absolutamente cruciais. As políticas de cotas para estudantes em escolas públicas e para negros no ensino superior podem ter esse efeito no médio prazo, e devem ser intensificadas e universalizadas no território nacional. Aspecto decisivo, e não atentado pelas discussões sobre o tema, é o de que alunos do ensino médio público que hoje o abandonam adotam atitude perfeitamen-

${ }^{23} \mathrm{O}$ investimento por aluno no ensino médio atingiu $20 \%$ do PIB per capita in 2009, contra 25\% nos países da OCDE. Isso representa o dobro da média dos anos 1990, que girou em torno de 10\%. Dados do Banco Mundial em http://data.worldbank.org/indicator/SE.XPD.SECO.PC.ZS. te racional. As chances de admissão no vestibular das melhores universidades, em sua maioria públicas, são diminutas, já que não há vagas para todos e a concorrência com jovens de classe média, oriundos de escolas privadas, é grande e desleal. O acesso ao ensino superior para aqueles jovens (em geral de classes sociais mais baixas) depende, em geral, do investimento no custeio dos estudos por parte do próprio estudante. Isso requer a entrada no mercado de trabalho, o que se dá em condições de competição também muito ruins: jovens de 18 anos, saídos do ensino médio de má qualidade, competem em condições muito desfavoráveis com os que já estão empregados e os que demandam emprego ao deixar a universidade. É isso que explica o salto na taxa "nem nem" de exclusão entre os 17 e os 18 anos, que vimos antes, para homens e mulheres igualmente. Parte substancial deles e delas se torna "nem nem" por não ter condições de acesso ao ensino superior, e por não ter poder de barganha no mercado de trabalho. Para esses jovens, a sociedade brasileira se apresenta como um ambiente enclausurado, condenando seu futuro.

As políticas de cotas, nessas condições, têm grande potencial transformador das chances de vida dos jovens das classes mais baixas. A perspectiva de entrar numa universidade pública, mesmo quando oriundos do ensino público, é um incentivo para a redução da evasão, ainda muito alta, que ocorre na passagem dos jovens das classes mais baixas do ensino fundamental para o médio. ${ }^{24}$ E a dedicação à própria qualificação média muda de sinal se há perspectivas reais de progressão nos estudos rumo ao ensino superior de qualidade. Um dos efeitos disso pode ser o aumento da pressão dos pais e dos próprios alunos para a melhoria do ensino público, pressões até aqui vistas como inócuas, já que a mobilidade escolar dos mais pobres encontrava no ensino médio um beco sem saída. Isso permite prever o aumento da pressão popular por melhoria do ensino público em geral.

No caso específico das mulheres jovens, é

${ }^{24}$ Estudos importantes dessas transições são Hasenbalg (2003); Torche e Ribeiro (2012). 
hora de se discutir a criação de creches nas escolas públicas do ensino médio. A incidência de "nem nem" entre as jovens de 15 anos com filhos é de mais de 70\%, e esse evento continuará cobrando seu preço no futuro dessas adolescentes. Educação sexual é, obviamente, crucial, mas ela não parece capaz de evitar a gravidez precoce nas camadas populares. Uma rede local de creches públicas, oferecida pelas prefeituras, poderia cumprir essa função, dando prioridade para crianças de jovens em idade escolar. Uma pesquisa que dimensione o problema em escala municipal, atenta às regiões do país, é estratégica para orientar uma política dessa natureza.

Inclusão emergencial via mercado, por meio de políticas de renda; investimentos na qualidade dos serviços públicos de educação, visando ao longo prazo; incentivos aos jovens para que permaneçam na escola (mesmo quando esta apresenta má qualidade no momento), como as políticas de cotas para o ensino superior (e também ao ensino técnico) e as de acessibilidade para jovens portadores de necessidades especiais; educação sexual para as adolescentes; num ambiente de incentivos ao crescimento econômico e à geração de empregos de qualidade: eis uma agenda de políticas públicas com potencial para desativar esse mecanismo gerador de desigualdades de longo prazo que é a taxa "nem nem" de exclusão.

Sugiro que essa taxa não produziu explosão social no país em razão da combinação entre caráter estrutural do problema e melhoria nas condições dos mercados de trabalho e educacional nos últimos anos. As variáveis de contexto, nessas duas dimensões, perderam muito de sua incidência, o que indica redução real de desigualdades intermunicipais e regionais. A hipótese, aqui, é a de que a melhoria das condições materiais de vida, ao se disseminar pelo país, contribuiu para reduzir a percepção de clausura das condições de mobilidade social, ampliando o horizonte de expectativas de inclusão dos jovens "nem nem", em especial as mulheres. Ao contrário, pois, de aparecer como deterioração de condições antes favoráveis e, portanto, como frustração de suas expectativas, como é hoje o caso de vários países europeus.

Por fim, mesmo correndo o risco de ver o diagnóstico negado pela história, expresso minhas dúvidas quanto ao fato de a população diretamente beneficiada pelas políticas públicas de inclusão em curso se sentir representada nos movimentos iniciados em junho de 2013, que apresentam nítido recorte de classe média, e, mais ainda, estudantil. Logo, não parece ser alimentada pela juventude "nem nem", hoje concentrada nas regiões e famílias mais pobres do país.

Recebido para publicação em 4 de maio de 2013 Aceito para publicação no dia 21 de junho de 2013

\section{REFERÊNCIAS}

ALVES, José Eustáquio R.; CAVENAGUI, Suzana M. Tendências demográficas, dos domicílios e das familias no Brasil. Publicado em http://www.ie.ufrj.br/aparte/pdfs/ tendencias demograficas e de familia 24ago12.pdf,2012. Acesso em fevereiro de $\overline{2} 0 \overline{1} 3$.

ANDERSON, Benedict. Comunidades imaginadas. Reflexiones sobre el origen y la difusión del nacionalismo. México: Fondo de Cultura Económica, 1993.

BERMAN, Marshall. Tudo que é sólido desmancha no ar A aventura da modernidade. São Paulo: Companhia das Letras, 1982.

BISILLIAT, Jane. (Org.). Regards des femmes sur la globalisation. Paris: Karthala, 2003.

BLAY, Eva A. Trabalho industrial X trabalho doméstico. A ideologia do trabalho feminino. Trabalho apresentado na XXVII Reunião Anual da SBPC, 1975, disponível em http: /educa.fcc.org.br/pdf/cp/n15/n15a02.pdf. Acesso em março de 2013.

BOURDIEU, Pierre. A distinção. Crítica social do julgamento. São Paulo: Edusp; Porto Alegre: Zouk, 2007 [1979].

BRADLEY, Harriet; VAN HOOF, Jacques (Eds.). Young people in Europe: labour markets and citizenship. Bristol: Policy Press, 2005.

CARDOSO, Adalberto. Ensaios de sociologia do mercado de trabalho brasileiro. Rio de Janeiro: FGV, 2013.

CIPOLLONE, Angela; PATACCHINI, Eleonora; VALLANTI, Giovanna. Women labor market performance in Europe: trends and shaping factors, 2012. Disponível em http:// www.neujobs.eu/sites/default/files/event/2012/03/VALLANTIREPORT_complete.pdf Acesso em dezembro de 2012.

COMIN, Alvaro A.; BARBOSA, Rogério J. Trabalhar para estudar: sobre a pertinência da noção de transição escolatrabalho no Brasil. Novos Estudos Cebrap, n. 91, p. 7595,2011 . DOI http://dx.doi.org/10.1590/S010133002011000300004.

COSTA, Dora L. From mill town to board room: the rise of women's paid labor. Journal of Economic Perspectives. v. 14, n. 4 , p. 101-122, 2000

CROUCH, Colin. Social change in western Europe. Oxford: 
Oxford University Press, 1999.

DEJOURS, Christophe. Centralité du travail et théorie de la sexualité. Adolescence, v. 14, n. 2, p. 9-29, 1996.

DELPHY, Christine. L'ennemi principal I. L'économie politique du patriarcat. Paris: Syllepse, 2008.

DOMBOIS, Rainer. ¿’Brasilianización” Global? Empleo atípico y regímenes de bienestar en Europa y América Latina. Revista Latinoamericana de Estudios del Trabajo, v 17, n. 28, p. 7-43, 2013.

DOMINGUES, José M. Gerações, modernidade e subjetividade coletiva. Tempo Social. v. 14, n. 1, p. 67-89, 2002.

EISENSTADT, Schmuel. From generation to generation. (Terceira edição aumentada), Nova York, Transaction Publishers, 2002 [1956].

ESTANQUE, Elísio; COSTA, Hermes; SOEIRO, José. The new global cycle of protest and the Portuguese case, Journal of Social Science Education, v.12, n.1, 2013.

FALQUET, Jules; HIRATA, Helena; KERGOAT, Danièle; LABARI, Brahim; LE FEUVRE, Nicky; SOW, Fatou. (Orgs.). Le sexe de la mondialisation. Genre, classe, race et nouvelle division du travail. Paris: Presses de Sciences Po, 2010.

GIDDENS, Anthony. As consequências da modernidade. São Paulo: Unesp, 1991.

GIVANS, Roberts; SOULE, Sarah. The diffusion of social movements. Cambridge: Cambridge University Press, 2011.

GOHN, Maria G.; BRINGEL, Breno M. (Orgs.). Movimentos sociais na era global. Petrópolis: Vozes, 2013.

HASENBALG, Carlos A.A transição da escola para o trabalho. In Hasenbalg, C.; Silva, N. V. Origens e destinos. Desigualdades sociais ao longo da vida. Rio de Janeiro: Topbooks, p. 147-172, 2003.

; SILVA, Nelson do V. Origens e destinos. Desigualdades sociais ao longo da vida. Rio de Janeiro: TopBooks, 2003.

HIRATA, Helena; KERGOAT, Danielle. Novas configurações da divisão sexual do trabalho. Cadernos de Pesquisa (Fundação Carlos Chagas), v. 37, n. 132, p. 595-609, 2007.

Nova divisão sexual do trabalho? Um olhar voltado para a empresa e a sociedade. São Paulo: Boitempo, 2002.

IBGE (2012). Pesquisa Nacional por Amostra de Domicílios 2011: Síntese de Indicadores. Rio de Janeiro, IBGE. Disponível em ftp://ftp.ibge.gov.br/Trabalho_e_Rendimento/ Pesquisa_Nacional_por_Amostra_de_Domicilios_anual/ 2011/Sintese_Indicadores/sintese_pnād2011.pdf. Acesso em março de 2013.

LAHIRE, Bernard. O homem plural. As molas da ação. Lisboa: Instituto Piaget, 2001.

LEÃO, Geraldo; DAYRELL, Juarez T.; REIS, Juliana B. Juventude, projetos de vida e ensino médio. Educação e Sociedade, v. 32, n. 117, p. 1067-1084, 2011.

LEONE, Eugenia T.; MAIA, Alexandre G.; BALTAR, Paulo E. Mudanças na composição das famílias e impactos sobre a redução da pobreza no Brasil. Economia e Sociedade, v. 19, n. 1 (38), p. 59-77, 2010.

MANNHEIM, Karl. El problema de las generaciones, 1928. (Disponível em http://www.reis. cis.es/REISWeb/PDF/ REIS_062_12.pdf).

MARX, Karl. O 18 Brumário de Luís Bonaparte. In: Os Pensadores: Marx. São Paulo: Abril Cultural, p. 323-404, 1978.

NONATO, Fernanda J.; PEREIRA, Rafael; NASCIMENTO, Paulo A.; ARAÚJO, Thiago C. O perfil da força de trabalho brasileira: trajetórias e perspectivas. In: Mercado de Trabalho n. 51, Brasília: IPEA, p. 30-41, 2012.
OECD. Women at work: who are they and how are they faring? In: Employment Outlook. Paris: OECD, 2002.

Education at a glance 2012: OECD indicators. OECD Publishing, http://dx.doi.org/10.1787/eag-2012-en, 2012.

ORTEGA Y GASSET, José. Juventude. In: A rebelião das massas. São Paulo: Martins Fontes, p. 239-248, 1987.

PINTO, José M. R. O acesso à educação superior no Brasil. Educação e Sociedade, v. 25, n. 88, p. 727-756, 2004.

PISSARIDES, Christopher; GARIBALDI, Pietro; OLIVETTI, Claudia; PETRONGOLO, Barbara; WASMER, Etienne. Women in the labour force: how well is Europe doing? European Women at Work, 21 jun. 2003, Alghero, Italy, 2003. Disponível em http://people.bu.edu/olivetti/ papers/women.pdf. Acesso em dezembro de 2012.

RIBEIRO, Carlos Antonio C. Desigualdade de oportunidades e resultados educacionais no Brasil. Dados, Revista de Ciências Sociais, v. 54, p. 41-88, 2011.

RUSSELL, Helen.; O'CONNELL, Philip J. Getting a Job in Europe: The Transition from Unemployment to Work among Young People in Nine European Countries. Work, Employment \& Society, v. 15, n. 1, p. 1-24, 2001.

SHILDRICK, Tracy; MACDONALD, Robert. Biographies of exclusion: poor work and poor transitions. International Journal of Lifelong Education, v. 26, n. 5, p. 589-604, 2007.

SILVA, Monica R.; PELISSARI, Lucas B.; STEINBACH, Allan A. Juventude, escola e trabalho: permanência e abandono na educação profissional técnica de nível médio. Educação e Pesquisa, 2012, disponível em http:// www.scielo.br/pdf/ep/2012nahead/aop899.pdf. Acesso em janeiro 2013.

SINGLY, Francois de. Fortunes et infortunes de la femme mariée. Sociologie de la vie conjugale. Paris: PUF, 1987.

SORJ, Bila; FONTES, Adriana; MACHADO, Danielle C. Políticas e Práticas de Conciliação entre Família e Trabalho no Brasil. Cadernos de Pesquisa (Fundação Carlos Chagas), v. 37, n. 132, p. 573-594, 2007.

STEIJN, Bram; NEED, Ariana; GESTHUIZEN, Maurice. Well begun, half done?: Long-term effects of labour market entry in the Netherlands, 1950-2000. Work, Employment \& Society v. 20, p. 453-472, 2006, doi:10.1177/ 0950017006066996.

THEVENON, Olivier. L'augmentation de l'activité des femmes en Europe: progrés de la conciliation ou polarisationdes comportements? Population (French Edition), v. 64, n. 2, Avril/juin, p. 263-303, 2009.

TOMÁS, Maria C.; OLIVEIRA, Ana Maria H.; RIOS-NETO, Eduardo L. Adiamento do ingresso no mercado de trabalho sob o enfoque demográfico: uma análise das regiões metropolitanas brasileiras. Revista Brasileira de Estudos Populacionais, v. 25, n. 1, p. 91-107, 2008.

TORCHE, Florencia; RIBEIRO, Carlos Antonio C. Parental wealth and children's outcomes over the life-course in Brazil: A propensity score matching analysis. Research in Social Stratification and Mobility, v. 30, p. 79-96, 2012.

VANTTAJA, Markku; JÄRVINEN, Tero. The young outsiders: the later life courses of 'drop-out youth'. International Journal of Lifelong Education, v. 25, n. 2, p. 173-184, 2006.

WOLBERS, Maarten H. J. Patterns of Labour Market Entry: A Comparative Perspective on School-to-Work Transitions in 11 European Countries. Acta Sociologica, v. 50, n. 3, p. 189-210, 2007. 


\section{YOUTH, WORK AND DEVELOPMENT: elements for an investigation agenda}

\section{Adalberto Cardoso}

The post-2008 economic crisis, accompanied by large social protests everywhere, turned on a stop light in the richer countries in terms of work and study opportunities for young people. The number of youth who neither study nor work increased greatly, especially in Spain and Greece, but this phenomenon has spread to the wealthier countries. This article shows that in Brazil the "nem nem" (neither nor) condition is structural and it proposes an analytical model to explain the transformations that occurred from 2000 to 2010. It suggest that the structural changes that the country went through and the public policies to lower the barriers to enter schools and the labor market reduced the impact of regional inequalities but increased the burden of poverty in explaining the "nem nem" condition of young people.

KEY WORDS: Youth. Labor market. Structural changes. "Nem nem" condition. Causal models.
JEUNESSE, TRAVAIL ET DÉVELOPPEMENT: éléments pour un programme d'investigation

\section{Adalberto Cardoso}

La crise économique d'après 2008, accompagnée un peu partout de grandes protestations sociales, a déclenché un signal d'alarme dans les pays plus riches quant aux opportunités de travail et d'étude pour les jeunes. Le nombre de ceux qui n'étudient ni ne travaillent a beaucoup augmenté, tout spécialement en Espagne et en Grèce, mais le phénomène s'est très répandu dans les pays riches. Larticle montre qu'au Brésil la condition « ni-ni » est structurelle et propose un modèle analytique pour expliquer les changements survenus entre 2000 et 2010 . Il montre que les changements structuraux subis par les pays et les politiques publiques de réduction des barrières d'accès à l'école et au marché de travail ont réduit l’impact des inégalités régionales et ont augmenté le fardeau de la pauvreté capable d'expliquer la condition de « ni-ni » des jeunes.

Mots-CLÉs: Jeunesse. Marché du Travail. Changements structuraux. Condition "ni ni". Modèles de causalité. da UERJ (IESP-UERJ). Pesquisador Associado do Centro Brasileiro de Análises e Planejamento e do Warwick Institute for Employment Research. Cientista do Nosso Estado da FAPERJ e Pesquisador 1 do CNPq. Atualmente coordena três projetos de pesquisa (dentre eles um PRONEX) e atua em diversas áreas da Sociologia do Trabalho, da Sociologia Urbana (incluindo desigualdades sociais) e da Teoria Social. Sua produção mais recente inclui “Ensaios de sociologia do mercado de trabalho", Rio de Janeiro, FGV, 2013, e "Brazil Emerging: inequality and emancipation”, New York, Routledge, 2013 (organizado com Jan Nederveen Pieterse). 